\title{
USO DE ÓLEOS ESSENCIAIS NO CONTROLE DOS SINAIS CLÍNICOS DAS DIARREIAS NEONATAIS EM LEITÕES NASCIDOS DE FÊMEAS COM DIFERENTES ORDENS DE PARTO
}

\section{USE OF ESSENTIAL OILS IN THE CONTROL OF CLINICAL SIGNS OF NEONATAL DIARRHEA IN PIGLETS BORN TO SOWS WITH DIFFERENT PARTURITION ORDERS}

\author{
Carlos Augusto Rossi ${ }^{1}$ \\ Marcelo Soares ${ }^{1}$ \\ Franciele Camila Luchese $^{2}$ \\ Janio Morais Santurio ${ }^{1}$ \\ ${ }^{1}$ Professores Doutores da Universidade Federal de Santa Maria, Santa Maria, RS, Brasil - \\ carlos.rossi.mv@gmail.com \\ ${ }^{2}$ Médica Veterinária, Mestre, Companhia Integrada de Desenvolvimento Agrícola de Santa Catarina, \\ Brusque, SC, Brasil.
}

\section{Resumo:}

Este estudo avaliou a emulsão líquida de óleos essenciais de orégano (Origanum vulgare) e alecrim (Rosmarinus officinalis labiatae) no controle dos sinais clínicos da diarreia neonatal em leitões. Foram monitorados 1.334 leitões lactentes, com peso vivo médio inicial de $1,5 \mathrm{~kg}$, quanto aos sinais clínicos de diarreia neonatal. O delineamento experimental foi o inteiramente casualizado e com três tratamentos (T): (T1) controle (solução fisiológica), (T2) mescla dos óleos essenciais e (T3) enrofloxacina. Os animais que receberam o T1 apresentaram sinais clínicos característicos de diarreia diferindo $(\mathrm{P}<0,01)$ dos demais tratamentos. O percentual de cura da diarreia dos leitões não diferiu $(\mathrm{P}>0,01)$ entre os tratamentos, independente da ordem de partos $(\mathrm{OP})$ das mães. Já leitões com sinais clínicos de diarreia, nascidos de fêmeas com OP inferior a três apresentaram maior percentual de cura $(74,6 \%)$, se comparados aos leitões diarreicos de fêmeas com OP entre três e cinco $(68,2 \%)$ e superior a cinco $(56,4 \%)$. As análises microbiológicas das fezes e histológicas do epitélio ileal não apresentaram diferenças $(\mathrm{P}>0,01)$ entre os tratamentos. A emulsão com óleos essenciais de orégano e alecrim $\left(2 \mathrm{~mL} \mathrm{~kg}^{-1}\right)$, para leitões entre zero e o oito dias de vida, pode vir a substituir a enrofloxacina no controle dos sinais clínicos das diarreias neonatais.

Palavras-Chave: enrofloxacina; Origanum vulgare; Rosmarinus officinalis labiatae.

\begin{abstract}
:
This study evaluated the liquid emulsion of oregano and rosemary essential oils in the control of neonatal diarrhea in piglets. We monitored 1334 piglets with average weight of $1.5 \mathrm{~kg}$ regarding the clinical signs of neonatal diarrhea. The design was completely randomized with three treatments (T): (T1) control (saline), (T2) essential oils and (T3) enrofloxacin. T1 showed characteristic
\end{abstract}


clinical signs of diarrhea differing $(\mathrm{P}<0.01)$ from other treatments. The cure rate of diarrhea was not different $(\mathrm{P}>0.01)$ between piglets receiving essential oils or antibiotic, regardless of the order of parturition of the sows. On the other hand, piglets with clinical signs of diarrhea born to sows with order of parturition less than three had a higher cure rate $(74.6 \%)$ compared with diarrheal piglets born to sows with order of parturition between three and five $(68.2 \%)$ and more than five (56.4\%). The counting of heterotrophic bacteria colony, Escherichia coli and Clostridium perfringens, and histological analyzes of the ileal epithelium showed no differences $(\mathrm{P}>0.01)$ among treatments. The emulsion with essential oils of oregano and rosemary $\left(2 \mathrm{~mL} \mathrm{~kg}^{-1}\right)$, for piglets between zero and eight days of age, might replace the enrofloxacin in controlling clinical signs of neonatal diarrhea.

Keywords: enrofloxacin; Origanum vulgare; Rosmarinus officinalis Labiatae.

Recebido em: 15 ago. 2012.

Aceito em: 25 set. 2014

\section{Introdução}

A superação contínua dos resultados técnicos é um desafio que caracteriza a rotina da moderna suinocultura. Vários foram os ganhos obtidos com o melhoramento genético, o aprimoramento dos conhecimentos sobre nutrição e sanidade, ambiência, instalações e reprodução. Não obstante, há vários desafios a serem vencidos em todos os setores da produção de suínos, pois, mesmo com as modernas ferramentas disponíveis, os recém-nascidos ainda sofrem com as diarreias neonatais ${ }^{(1)}$.

As diarreias, assim como outras doenças que acometem o trato digestório dos suínos, são multifatoriais e os principais agentes envolvidos são o Clostridium perfringens tipo A ou tipo C, a Escherichia coli enterotoxigênica, a Isospora suis, o rotavírus e o vírus da gastroenterite transmissível dos leitões ${ }^{(2)}$. Em uma rápida reflexão sobre a ocorrência das diarreias nas granjas de suínos, o que determina a importância desses episódios são fatores como o número de doentes, o curso da doença, o grau de desidratação dos leitões afetados, a mortalidade especificamente devida ao problema, a repetição de episódios em diferentes lotes e as quantidades e eficiência das medicações e vacinações em curso ${ }^{(3)}$.

As diarreias desenvolvem-se com sintomatologia clínica de perda de solutos e água, depleção de eletrólitos, desequilíbrio ácido-básico e desidratação, que pode ser fatal se não tratada adequadamente $^{(4)}$. Os tratamentos são difíceis, de custos elevados e muitas vezes ineficientes, porém a prevenção e o manejo adequado são formas eficazes de reduzir a incidência de diarreia.

A necessidade de garantir os resultados zootécnicos e econômicos da produção de suínos incentivou a incorporação rotineira de antimicrobianos (promotores de crescimento) nas rações destinadas às fases do processo produtivo. Nesse sentido, novas alternativas que garantam o desempenho animal, a qualidade do produto final e a redução de resíduos indesejáveis à saúde do consumidor estão sendo cientificamente consideradas. Pesquisas têm sido realizadas com prebióticos, enzimas, ácidos orgânicos e extratos vegetais. Estes últimos, representados pelos óleos essenciais, são formados por uma mistura complexa de substâncias voláteis, geralmente lipofílicas, que possuem componentes como hidrocarbonetos terpênicos, alcoóis simples, aldeídos, cetonas, fenóis, ésteres e ácidos orgânicos(5). 
Os efeitos observados in vitro são vários, o que justifica as pesquisas para determinar as combinações e níveis de inclusão dos óleos essenciais às dietas ou o desenvolvimento de produtos, de uso oral, para melhorar o desempenho e a produção animal ${ }^{(6)}$. Os óleos essenciais interferem na microbiota intestinal (efeito antimicrobiano), melhoram a digestibilidade e a absorção dos nutrientes, além de estimularem a resposta imune e induzir modificações morfo-histológicas do trato gastrintestinal ${ }^{(5)}$.

Pelas propriedades individuais e ação sinérgica de seus princípios ativos, o uso de óleos essenciais, administrados via ração, pode melhorar a resposta imune de leitões lactentes. Embora existam informações positivas relacionadas ao sinergismo dos constituintes dos óleos essenciais, seu uso no controle dos sinais clínicos das diarreias neonatais de leitões é incipiente e pouco conclusivo. Assim, o objetivo deste trabalho foi avaliar a eficiência da substituição da enrofloxacina por uma mescla líquida de óleos essenciais de orégano e alecrim, via oral, em leitões lactentes entre o nascimento e o oitavo dia de vida.

\section{Material e Métodos}

Objetivou-se com o presente estudo avaliar o efeito terapêutico de um produto comercial constituído de $5 \%$ de orégano (Origanum vulgare) (60\% de carvacrol e $15 \%$ de timol), $2 \%$ de alecrim (Rosmarinus officinalis labiatae) e veículo inerte aquoso, no tratamento das gastrenterites neonatais de leitões. A seleção dos óleos essenciais foi realizada a partir de pesquisas prévias realizadas in vitro com frangos de corte ${ }^{(7)}$. O experimento foi realizado em granja comercial $\left(29^{\circ}\right.$ $37^{\prime} 35.95^{\prime \prime}$ latitude sul e $56^{\circ} 32^{\prime} 29.85^{\prime \prime}$ longitude oeste), no período entre novembro e dezembro de 2011.

O trabalho foi aprovado pelo comitê de ética sob o número 031/2009. Foram utilizadas 112 fêmeas suínas geneticamente homogêneas com ordens de parto entre um e oito, alojadas em celas parideiras individualizadas e distribuídas em cinco salas. As fêmeas, independente da ordem de partos, e seus leitões foram mantidos dentro da zona de conforto térmico para cada categoria. Foram monitorados, quanto aos sinais clínicos de diarreia neonatal, 335 leitões machos e fêmeas, híbridos lactentes, com peso vivo médio inicial de $1,5 \mathrm{~kg}$.

Os leitões com sinais clínicos evidentes de diarreia neonatal e dentro da mesma leitegada foram distribuídos em três tratamentos: T1 (controle) (avaliados 63 leitões lactentes diarreicos entre zero e sete dias de vida, os quais receberam solução fisiológica, $3 \mathrm{~mL} \mathrm{~kg}^{-1}$, via oral, após 24 horas do diagnóstico clínico de diarreia); T2 (óleos essenciais) (avaliados 148 leitões lactentes diarreicos, os quais receberam emulsão líquida a $5 \%$ de óleos essenciais, via oral, $2 \mathrm{~mL} \mathrm{~kg}^{-1}, 24$ horas após o diagnóstico clínico de diarreia durante três dias consecutivos; e T3 (enrofloxacina) (avaliados 124 leitões lactentes diarreicos, os quais receberam enrofloxacina (Referência: 0003836, Fabricante: Fabiani Saúde Animal), a 5\%, via oral, na dose de $1 \mathrm{~mL} \mathrm{~kg}^{-1}$ de peso vivo, 24 horas após o diagnóstico de diarreia durante 3 dias consecutivos). O delineamento experimental utilizado foi o inteiramente casualizado, sendo considerado cada leitão como unidade experimental. Os leitões foram avaliados individualmente, duas vezes ao dia (9:00 e 18:00 horas), quanto à evidência de sinais clínicos de diarreia. A consistência das fezes foi classificada de 1 a 4 (1 - líquidas; 2 líquidas/pastosas; 3 - pastosas e 4 - sólidas) ${ }^{(8)}$. 
Para a análise histológica do epitélio intestinal foram eutanasiados $\left(0,3 \mathrm{~mL} \mathrm{~kg}^{-1}\right.$ de Iodeto de mebezônio via intracardíaca) 60 leitões subdivididos na necropsia em 5 grupos de 12 leitões de acordo com cada tratamento, em um delineamento inteiramente casualizado com cinco tratamentos: T1a - controle (leitões diarreicos que receberam solução fisiológica e sem redução do quadro sintomático clínico de diarreia; T2a - leitões diarreicos que receberam óleos essenciais de orégano e alecrim sem redução do quadro sintomático clínico de diarreia; T2b - leitões diarreicos que receberam óleos essenciais de orégano e alecrim e com redução do quadro sintomático clínico de diarreia; T3a - leitões diarreicos que receberam enrofloxacina sem redução do quadro sintomático clínico de diarreia; T3b - leitões diarreicos que receberam enrofloxacina e com redução do quadro sintomático clínico de diarreia.

Após a eutanásia de cada animal foi coletado um segmento do íleo ( $5 \mathrm{~cm}$ de comprimento), aberto ao longo do mesentério, lavado em solução fisiológica e a serosa do segmento intestinal fixada em papelão com grampos. As amostras foram acondicionadas em frascos contendo formol tamponado a $10 \%$ e enviadas ao laboratório de histologia do departamento de morfologia da Universidade Federal de Santa Maria (UFSM). No laboratório, as amostras foram colocadas em blocos de parafina purificada. Após a secagem dos blocos, foram feitos cortes de cinco micrômetros e, de cada amostra colhida, duas lâminas e, em cada lamina, um corte não seriado. Essas lâminas foram coradas por hematoxilina e eosina. Em cada lâmina foi realizada a média e o desvio padrão da altura $(\mathrm{mm})$ das vilosidades e profundidade $(\mathrm{mm})$ das criptas correspondentes, por meio de microscopia de luz com aumento de 40 vezes. As medidas das vilosidades foram tomadas a partir da região basal que coincide com a porção superior das criptas percorrendo-a longitudinalmente até seu ápice. As criptas foram medidas da sua base até a região de transição cripta/vilosidade. Para a análise morfométrica, foi utilizado o Sistema de Processamento e Análise de Imagens, associado a um microscópio binocular, com câmara de vídeo colorida, acoplada para aquisição de imagens microscópicas.

De cada leitão eutanasiado foi coletada, também, um grama de conteúdo fecal do íleo e acondicionados em frascos contendo glicerina tamponada (diluição $10^{-1}$ ) como meio de transporte. As amostras foram enviadas ao laboratório de microbiologia do Departamento de Microbiologia e Parasitologia/UFSM. No laboratório, as amostras foram identificadas e quantificadas quanto à presença de microrganismos heterotróficos $\left(\mathrm{UFC} . \mathrm{mL}^{-1}\right.$ ), coliformes totais (NMP.g ${ }^{-1}$ ), coliformes fecais (NMP.g ${ }^{-1}$ ), bactérias Gram (UFC.mL ${ }^{-1}$ ), Salmonella spp. (NMP.g ${ }^{-1}$ ), E. coli (UFC.mL ${ }^{-1}$ ) e Clostridium perfringens (UFC. $\mathrm{mL}^{-1}$ ), conforme descrição na literatura ${ }^{(9)}$.

Para o parâmetro índice de cura das diarreias neonatais, cada leitão representou uma repetição. Essas unidades de repetição foram classificadas em grupos conforme a ordem de parição (até três, entre três e cinco e acima de cinco partos) das fêmeas suínas mães e o efeito da ordem de partos sobre os parâmetros avaliados foi analisado. Os dados obtidos foram submetidos ao teste do Quiquadrado com nível de significância inferior a $0,05 \%$, utilizando-se o programa estatístico SAS ${ }^{(10)}$. Para as análises de microbiologia e morfologia intestinal, foi utilizado o teste de dados não paramétricos Kruskal-Wallis com nível de significância inferior a 0,05\%, utilizando-se o programa estatístico Minitab $^{(11)}$. 


\section{Resultados e Discussão}

Os leitões do grupo controle (T1) não apresentaram redução dos sinais clínicos evidentes de diarreia (Tabela 1) durante a primeira semana de vida, o que diferiu $(\mathrm{P}<0,01)$ dos demais tratamentos.

O índice de cura dos leitões diarreicos tratados com óleos essenciais e enrofloxacina foi 81,76\% e $84,68 \%$, respectivamente, não diferindo $(\mathrm{P}>0,01)$ entre ambos os tratamentos. Os resultados obtidos podem indicar que os princípios ativos da mescla de óleos essenciais e do antibiótico atuaram de forma similar, mas através de mecanismos distintos. A enrofloxacina inibe irreversivelmente a enzima bacteriana girase, exercendo efeito letal sobre a bactéria num período muito breve, atingindo níveis terapêuticos no sangue e nos órgãos dos animais após uma hora da administração ${ }^{(12)}$.

Tabela 1: Índice de cura da diarreia na primeira semana de vida em leitões dos grupos controle, tratados com óleos essenciais ou antibiótico

\begin{tabular}{lllll}
\hline Tratamentos & NLC/TLD & $\mathbf{\%}^{*}$ & $\mathbf{X}^{\mathbf{2}}$ & $\mathbf{P}$ \\
\hline Controle & $0 / 63$ & $0^{\mathrm{b}}$ & - & - \\
Óleos essenciais & $121 / 148$ & $81,76^{\mathrm{a}}$ & 161,14 & 0,01 \\
Antibiótico & $105 / 124$ & $84,68^{\mathrm{a}}$ & - & - \\
\hline
\end{tabular}

NLC - $\mathrm{n}^{\circ}$ de leitões curados da diarreia após o tratamento; TLD - total de leitões com diarreia neonatal; *percentagem de cura; $\mathrm{X}^{2}$ teste do Qui Quadrado; a,bletras diferentes entre tratamentos $(\mathrm{P}<0,05)$.

Os óleos essenciais estão relacionados à função antimicrobiana, atividade antioxidante e proteção celular, principalmente em eritrócitos e leucócitos ${ }^{(13)}$. O efeito antimicrobiano dos óleos essenciais está relacionado à sensibilização da bicamada fosfolipídica da membrana celular do microrganismo, causando aumento da permeabilidade e perdas de constituintes intracelulares vitais ou ainda danos nos sistemas enzimáticos deste microorganismo ${ }^{(14)}$.

Tabela 2: Índice de cura da diarreia na primeira semana de vida em leitões dos grupos controle, tratados com óleos essenciais ou antibiótico, nascidos de fêmeas com diferentes ordens de parto

\begin{tabular}{cccccccccc}
\hline \multirow{2}{*}{ OPF } & \multicolumn{2}{c}{ Controle } & \multicolumn{3}{c}{ Óleos essenciais } & \multicolumn{2}{c}{ Enrofloxacina } & \multirow{2}{*}{$\mathbf{X}^{\mathbf{2}}$} & \multirow{2}{*}{ P } \\
\cline { 2 - 7 } & NLC/TLD & \%* $^{*}$ & NLC/TLD & \%* $^{*}$ & NLC/TLD & \% $^{*}$ & & \\
\hline$<3$ & $0 / 10$ & $0^{\mathrm{b}}$ & $43 / 56$ & $76,8^{\mathrm{a}}$ & $45 / 52$ & $86,5^{\mathrm{a}}$ & 33,4 & $<0,01$ \\
3 a 5 & $0 / 25$ & $0^{\mathrm{b}}$ & $55 / 65$ & $84,6^{\mathrm{a}}$ & $35 / 42$ & $83,3^{\mathrm{a}}$ & 66,1 & $<0,01$ \\
$>5$ & $0 / 28$ & $0^{\mathrm{b}}$ & $23 / 27$ & $85,2^{\mathrm{a}}$ & $25 / 30$ & $83,3^{\mathrm{a}}$ & 54,2 & $<0,01$ \\
\hline
\end{tabular}

OPF - ordem de partos da fêmea suína; NLC - $\mathrm{n}^{\circ}$ de leitões curados da diarreia após o tratamento; TLD total de leitões com diarreia neonatal; * percentagem de cura; $\mathrm{X}^{2}$ teste do Qui Quadrado; a,b - letras diferentes entre tratamentos $(P<0,05)$.

Esse efeito foi comprovado em estudo in vitro em que o carvacrol 25\% e o timol $5 \%$ atuaram sobre a integridade da parede celular de bactérias gram-negativas causando ruptura da capa externa ${ }^{(15)}$. O percentual de cura da diarreia da primeira semana não mostrou diferenças $(\mathrm{P}>0,01)$ entre os leitões que receberam óleos essenciais ou antibiótico, independente da ordem de partos das matrizes, sendo 
o índice médio de $82,2 \%$ e $84,4 \%$ de cura, respectivamente (Tabela 2). No entanto, leitões com sinais clínicos de diarreia, nascidos de fêmeas com ordens de parto inferior a três, apresentaram maior percentual de cura $(74,6 \%)$ se comparados aos leitões diarreicos nascidos de fêmeas entre o terceiro e quinto partos $(68,2 \%)$ e superior a cinco partos $(56,4 \%)$. Estes últimos apresentaram percentual de cura menor $(\mathrm{P}<0,01)$ que leitões nascidos de fêmeas de ordens de parto inferior a cinco.

O controle sintomatológico da diarreia da primeira semana de vida dos leitões conforme a ordem de parição pode estar vinculado à eficiência imunitária das fêmeas suínas. Assim, de acordo com a literatura, as fêmeas de primeiro parto apresentam menor concentração de imunoglobulina $G$ $\left(49,9 \pm 7,9 \mathrm{mg} \mathrm{mL}^{-1}\right)$ em relação às fêmeas de segundo $\left(92,7 \pm 5,9 \mathrm{mg} \mathrm{mL}^{-1}\right)$, terceiro $(70,7 \pm 5,6 \mathrm{mg}$ $\left.\mathrm{mL}^{-1}\right)$ e quarto partos $\left(85,6 \pm 9,0 \mathrm{mg} \mathrm{mL}^{-1}\right)$. No entanto, os resultados obtidos neste trabalho, na relação percentual de cura de leitões com diarreia, demonstram diferenças $(\mathrm{P}<0.05)$ entre as ordens maiores e menores que cinco partos. Estes resultados podem ser atribuídos ao conjunto de imunoglobulinas e óleos essenciais, que podem ter atuado sinergicamente através das propriedades antimicrobianas e imunoestimulantes. Walter e Bilkei ${ }^{(16)}$, mostraram resultados positivos de um composto comercial à base de orégano sobre a imunidade de suínos em fase de crescimento e terminação. No mesmo trabalho foi observado maior ganho diário de peso e melhor conversão alimentar dos suínos tratados.

As análises histológicas do epitélio ileal de leitões diarreicos curados e de não curados não apresentaram diferenças $(\mathrm{P}>0,01)$ entre os tratamentos (Tabela 3). Para todos os leitões dos tratamentos avaliados, a altura das vilosidades intestinais e a profundidade das criptas estavam adequadas e mostraram-se altamente eficientes na absorção de nutrientes, semelhante aos dados observados na literatura $^{(5)}$. Segundo Vannucci e Guedes ${ }^{(3)}$, o que deve ser evidenciado é que a manutenção/otimização do equilíbrio intestinal é garantia de resultados técnicos e econômicos $\mathrm{O}$ equilíbrio intestinal, por sua vez, é estabelecido quando dois processos citológicos estão ocorrendo simultaneamente sem desvios: a renovação celular (proliferação e diferenciação), resultante das divisões mitóticas das células localizadas na cripta e ao longo dos vilos e a perda de células (extrusão), que ocorre no ápice dos vilos ${ }^{(3)}$. O balanço entre esses dois processos determina $o$ turnover constante (síntese-migração-extrusão), que define o equilíbrio intestinal. Essa percepção, portanto, deve ser levada em conta nas diferentes fases da vida do suíno, mas, paralelamente, é necessário também reconhecer que os desafios para a garantia da integridade intestinal têm características distintas nas fases.

Deve-se enfatizar que muitos fatores se apresentam como responsáveis por essa desorganização. Estes podem ser intrínsecos ou extrínsecos, ou seja, ligados à idade do animal, estado sanitário, perfil das enzimas gastrintestinais (maturação do trato digestório) ou relacionadas à alimentação, limpeza, ambiente e aos agentes patogênicos específicos ${ }^{(17)}$. Nesse sentido, o intestino em equilíbrio abriga uma complexa, densa, dinâmica e diversificada comunidade de microrganismos ${ }^{(4)}$. A composição da microbiota é regularmente constante, mas esse perfil pode ser alterado pela idade, tipo de dieta, ambiente, estresse e utilização de medicamentos ${ }^{(18)}$. Essa diversidade teórica na composição da microbiota foi evidenciada no presente trabalho (Tabela 4), e não apresentou diferenças $(\mathrm{P}>0,01)$ entre os tratamentos avaliados. 
Tabela 3: Altura das vilosidades (AV), profundidade das criptas (PC) e relação $\mathrm{AV}: \mathrm{PC}$ da mucosa do intestino delgado de leitões dos grupos controle, tratados com óleos essenciais ou antibiótico

\begin{tabular}{cccc}
\hline $\begin{array}{c}\text { Tratamentos } \\
\text { (T) }\end{array}$ & $\begin{array}{c}\text { Altura de vilosidades } \\
(\mathbf{A V}) \mathbf{( m m})\end{array}$ & $\begin{array}{c}\text { Profundidade de cripta } \\
\mathbf{( P C )}(\mathbf{m m})\end{array}$ & $\begin{array}{c}\text { Relação } \\
\mathbf{A V}: \mathbf{P C}\end{array}$ \\
\hline T1a & 244,19 & 154,56 & 1,58 \\
T2a & 244,60 & 154,52 & 1,58 \\
T2b & 244,52 & 154,49 & 1,58 \\
T3a & 244,23 & 154,61 & 1,58 \\
T3b & 244,61 & 154,56 & 1,58 \\
\hline Dpr & 0,43 & 0,23 & 0,03 \\
Probabilidade & & & 0,62 \\
T & 0,40 & 0,77 & \\
\hline
\end{tabular}

T1a - controle (leitões diarreicos que receberam solução físiológica e sem redução do quadro sintomático clínico de diarreia; T2a - leitões diarreicos que receberam óleos essenciais de orégano e alecrim sem redução do quadro sintomático clínico de diarreia; $\mathrm{T} 2 \mathrm{~b}$ - leitões diarreicos que receberam óleos essenciais de orégano e alecrim e com redução do quadro sintomático clínico de diarreia; T3a - leitões diarreicos que receberam enrofloxacina sem redução do quadro sintomático clínico de diarreia; T3b - leitões diarreicos que receberam enrofloxacina e com redução do quadro sintomático clínico de diarreia. Equação de regressão para a altura de vilosidades $\left(\mathrm{Y}_{\mathrm{ij}}=244-0,047 \mathrm{~T}\right)$; Equação de regressão para a profundidade de cripta $\left(\mathrm{Y}_{\mathrm{ij}}=155+0,008 \mathrm{~T}\right)$; Equação de regressão para a Relação AV:PC ( $\left.\mathrm{Y} i \mathrm{j}=1,58+0,0002 \mathrm{~T}\right)$; KruskalWallis Test - $\mathrm{AV}(\mathrm{P}=0,2) ; \mathrm{PC}(\mathrm{P}=0,95) ; \mathrm{AV}: \mathrm{PC}(\mathrm{P}=0,28)$.

Tabela 4: Análises das bactérias intestinais, região do íleo, de leitões dos grupos controle e tratados com óleos essenciais ou antibiótico

\begin{tabular}{|c|c|c|c|c|c|c|c|}
\hline \multirow{2}{*}{$\begin{array}{c}\text { Tratamentos } \\
\text { (T) }\end{array}$} & \multicolumn{7}{|c|}{ Bactérias intestinais } \\
\hline & $\mathrm{CBH}$ & CT & LATB & COF & CNFEcoli & CCP & BG \\
\hline 1 & 53000 & 108,3 & 1,25 & 102,8 & 1,75 & 757 & 3,25 \\
\hline 2 & 405000 & 282,0 & 1,41 & 282,0 & 1,58 & 4848 & 2,50 \\
\hline 3 & 27500 & 321,0 & 1,25 & 301,0 & 1,58 & 6374 & 4,50 \\
\hline 4 & 170000 & 128,5 & 1,25 & 128,5 & 1,83 & 2,965 & 3,41 \\
\hline $\mathrm{H}^{*}$ & 0,52 & 0,77 & 1,18 & 0,77 & 0,10 & 0,89 & 4,91 \\
\hline \multicolumn{8}{|l|}{ Probabilidade* } \\
\hline $\mathrm{T}$ & 0,91 & 0,85 & 0,75 & 0,85 & 0,99 & 0,82 & 0,17 \\
\hline \multicolumn{8}{|c|}{ 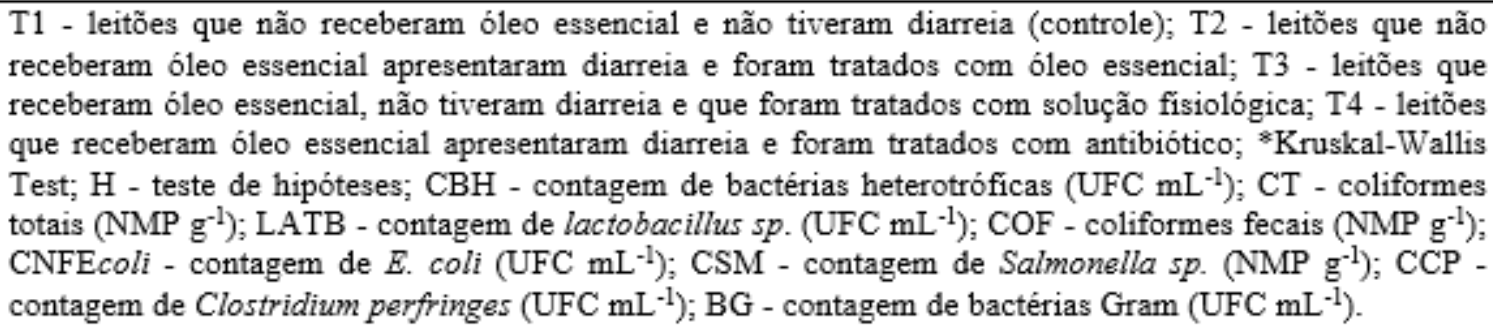 } \\
\hline
\end{tabular}

Assim, sugere-se que os fatores fisiológicos e ambientais têm importante papel na estabilização da microbiologia intestinal e no estabelecimento de uma população nativa. $\mathrm{O}$ pH relativamente alto no estômago de leitões, logo após o nascimento, decorrente da insuficiente secreção de ácido clorídrico, permite que bactérias tolerantes a este $\mathrm{pH}$ colonizem diferentes seções do trato intestinal $^{(4)}$. Em leitões lactentes, o pH decresce com a produção de ácido láctico e somente 
bactérias resistentes ao ambiente ácido persistem e se proliferam no intestino proximal, ocasionando maior proteção contra a penetração de patógenos sensíveis ao meio ácido ${ }^{(19)}$. Embora tenha sido relatada a presença de E. coli no intestino de leitões duas horas após o nascimento, normalmente a análise histológica de amostras de intestino de animais afetados pelas toxinas termolábil (LT) e termoestável (ST) produzidas por cepas de E. coli não mostra lesões ${ }^{(20)}$, e a mucosa do intestino delgado apresenta-se sem alterações ${ }^{(19)}$. A microbiota do intestino delgado do leitão é dominada por espécies aeróbias e anaeróbias facultativas ${ }^{(3)}$. Este ecossistema é uma unidade metabólica ativa que provê produtos essenciais para o hospedeiro, forma uma barreira contra agentes patogênicos e tem uma importante ação na morfologia do intestino, no desenvolvimento da imunidade, na digestão de nutrientes e também na modulação da expressão gênica do hospedeiro ${ }^{(21)}$. Diante do desequilíbrio dessa microbiota, os sinais clínicos mostram grandes dimensões negativas. As mudanças morfológicas na ausência de microbiota incluem a redução da massa intestinal, alteração no comprimento e na espessura do intestino e um ceco de maior dimensão com uma mucosa igualmente mais fina.

No nível histológico, a ausência da microbiota está associada às criptas mais curtas e às vilosidades menos espessas. As criptas mais rasas são um reflexo do índice mitótico reduzido e do turnover celular limitado ${ }^{(22)}$. Quando o intestino responde a algum agente com desequilíbrio, no turnover ocorre uma modificação na altura dos vilos, com danos ao funcionamento do órgão. Processos que incrementam a taxa de mitose com ausência, diminuição ou manutenção da taxa de extrusão, determinam aumento na altura dos vilos até um pregueamento da parede dos mesmos. Se o estímulo levar a um aumento da taxa de extrusão, havendo manutenção ou diminuição da taxa de proliferação, o intestino deverá responder com redução na altura dos vilos e, consequentemente, menor eficiência digestiva e de absorção ${ }^{(21)}$. Na caracterização de um desequilíbrio intestinal, as diarreias aparecem comumente como um importante sinal da complexidade do processo. Assim, a dinâmica intestinal é contínua, com respostas imunes de intensidades diferentes sobre substâncias ou agentes ofensivos e inofensivos ${ }^{(4)}$. Esses desafios impostos, muitas vezes por ações multifatoriais, recursos nutricionais ou alimentares podem ser interessantes para acelerar a recuperação de eventuais danos no sistema digestório. Para tanto, mais estudos são necessários para se avaliar os níveis ideais de inclusão e melhores combinações dos óleos essenciais, tendo em vista a possibilidade de serem alternativas de controle dos sinais clínicos das diarreias neonatais dos leitões.

\section{Conclusão}

Os resultados obtidos indicam que o antibiótico enrofloxacina pode vir a ser substituído por uma mescla de óleos essenciais, na dose de $2 \mathrm{~mL} \mathrm{~kg}^{-1}$, administrado via oral para leitões entre zero e o oito dias de vida, no controle dos sinais clínicos das diarreias neonatais.

\section{Referências}

1. Abrahão AAF, Vianna WL, Oliveira LF, Carvalho S, de Sant'Anna Moretti A. Causas de mortalidade de leitões neonatos em sistema intensivo de produção de suínos. [Preweaning piglets mortality in an intensive swine production system] Brazilian Journal of Veterinary Research and 
Animal Science. [Internet] 2004:41(2)88-91. Available from: http://www.scielo.br/pdf/bjvras/v41n2/25223.pdf Portuguese.

2. Yaeger MJ, Kinyon JM, Songer JGA. Prospective, case control study evaluating the association between Clostridium Difficile toxins in the colon of neonatal swine and gross and microscopic lesions. Journal of Veterinary Diagnostic Investigation. [Internet] 2007:19(1)52-59. Available from: http://vdi.sagepub.com/content/19/1/52.abstract Portuguese.

3. Vannucci FA, Guedes RMC. Fisiopatologia das diarreias em suínos. [Pathophysiology of swine diarrhea] Ciência Rural. [Internet] 2009:39(7)2233-42. Available from: http://www.scielo.br/scielo.php?pid=S0103-84782009000700047\&script=sci_arttext Portuguese.

4. Zlotowski P, David Driemeier D, Barcellos DESN. Patogenia das diarreias dos suínos: modelos e exemplos. [Pathogenesis of diarrhoea in pigs: models and examples] Acta Scientiae Veterinariae. [Internet] 2008:36(1)81-86. Available from: http://sumarios.org/sites/default/files/pdfs/50358_5937.PDF Portuguese.

5. Costa LB, Tse MLP, Miyada VS. Extratos vegetais como alternativas aos antimicrobianos promotores de crescimento para leitões recém-desmamados. [Herbal extracts as alternatives to antimicrobial growth promoters for weanling pigs] Revista Brasileira de Zootecnia. [Internet] 2007:36(3)589-95. Available from: http://www.scielo.br/pdf/rbz/v36n3/a11v36n3.pdf Portuguese.

6. Hernandez F, Madrid J, Garcia V, Orengo J, Megias M. Influence of two plant extracts on broilers performance, digestibility, and digestive organ size. Poultry Science. [Internet] 2004:83(2)169-74. Available from: http://ps.fass.org/content/83/2/169.abstract Portuguese.

7. Santurio, D.F.; Costa, M.M.; Maboni, G.; Cavalheiro, C.P.; De Sá, M.F.; Pozzo, M.D. et al. Atividade antimicrobiana de óleos essenciais de condimentos frente a amostras de Escherichia coli isoladas de aves e bovinos. [Antimicrobial activity of spice essential oils against Escherichia coli strains isolated from poultry and cattle] Ciência Rural. [Internet] 2011:41(6)1051-56. Available from: http://www.scielo.br/pdf/cr/2011nahead/a0511cr4430.pdf Portuguese.

8. Corassa A, Lopes DC, Bellaver C. Mananoligossacarídeos, ácidos orgânicos e probióticos para leitões de 21 a 49 dias de idade. [Mannanoligosaccharides, organic acids and probiotics for piglets from 21 to 49 days of age] Archivos de Zootecnia. [Internet] 2012:61(235) 467-76. Available from: http://scielo.isciii.es/pdf/azoo/v61n235/art15.pdf Portuguese.

9. Pedroso AA, Oetting LL, Utiyama CE, Fernando J, Menten M, lambais MR, et al. Variabilidade espacial da comunidade bacteriana intestinal de suínos suplementados com antibióticos ou extratos herbais. [Spacial variability of intestinal bacterial population of swine supplemented with antimicrobial or herbal extracts] Revista Brasileira de Zootecnia. [Internet] 2005:34(4)1225-33. Available from: http://www.scielo.br/pdf/rbz/v34n4/26393.pdf Portuguese.

10. Sas II. SAS OnlineDoc ${ }^{\circledR}$. Cary, NC. [Internet] 2000:8. Available from: http://smoo.ciagri.usp.br/sasdoc/sasdoc/sashtml/onldoc.htm Portuguese.

11. Mckenzie J, Goldman RN. The student edition of minitab for windows manual. Softcover ed. Addison-Wesley Longman, Incorporated, Belmont. [Internet] 1999:12. Available from: http://www.minitab.com/pt-br/products/minitab/education/ Portuguese.

12. Sanphar. Enrofloxacina em solução a 10\%. Catálago de produtos. S/A. São Paulo [Internet] 2008. Available from: http://www.sanphar.com.br/catalogo/showquestion.asp?fldAuto=103\&keepThis=true\&TB iframe= true Portuguese.

13. Burt S. Essential oils: their antibacterial properties and potential applications in foods: a review. International Journal of Food Microbiology. [Internet] 2004:94(3)223-53. Available from: http://www.sciencedirect.com/science/article/pii/S0168160504001680 Portuguese. 
14. Singh N, Singh RK, Bhunia AK, Stroshine RL. Efficacy of chlorine dioxide, ozone, and thyme essential oil or a sequential washing in killing Escherichia coli O157:H7 on lettuce and baby carrots. Food Science and Technology [Internet] 2002:35(8)720-29. Available from: http://www.sciencedirect.com/science/article/pii/S0023643802909333 Portuguese.

15. Lambert RJW, Skandamis PN, Coote PJ, Nychas GJE. A study of the minimum inhibitory concentration and mode of action of oregano essential oil, thymol and carvacrol. Journal of Applied Microbiology [Internet] 2001:91(3)453-62. Available from: http://dx.doi.org/10.1046/j.13652672.2001.01428.x Portuguese.

16. Walter BM, Bilkei G. Immunostimulatory effect of dietary oregano etheric oils on lymphocytes from growth-retarded, low-weight growing-finishing pigs and productivity. Tijdschr Diergeneeskd. [Internet] 2004:15(129)178-81. Available from: http://www.ncbi.nlm.nih.gov/pubmed/15052959 Portuguese.

17. Da Silva CA, De Brito BG, Mores N, Do Amaral AL. Ecopatologia da diarréia pós-desmame em granjas de suínos da região norte do Paraná, Brasil. [Ecopathology of postweaning diarrhoea in pig farms of north Paraná state, Brazil] Ciência Rural. [Internet] 1999:29(1)39-43. Available from: http://www.scielo.br/pdf/cr/v29n1/a08v29n1.pdf Portuguese.

18. Fuller R. Probiotics in man and animals. Journal of Applied Bacteriology. [Internet] 1989:66(1)365-78. Available from: http://onlinelibrary.wiley.com/doi/10.1111/j.13652672.1989.tb05105.x/pdf Portuguese.

19. Cooper VL. Diagnosis of neonatal pig diarrhea. Veterinary Clinics of North America: Food Animal Practice. [Internet] 2000:16(1)117-133. Available from: http://jas.fass.org/cgi/content/abstract/79/9/2367 Portuguese.

20. Österlundh I, Hultén F, Johannisson A, Magnusson U. Sows intramammarily inoculated with Escherichia coli at parturition: I functional capacity of granulocytes in sows affected or nonaffected by clinical mastitis. Veterinary Immunology and Immunopathology. [Internet] 2002:90(12)35-44. Available from: http://www.sciencedirect.com/science/article/pii/S0165242702002040 Portuguese.

21. Hooper LV, Wong MH, Thelin A, Hansson L, Falk PG, Gordon JI. Molecular analysis of commensal host-microbial relationships in the intestine. Science. [Internet] 2001:291(5505)881-84. Available from: http://www.sciencemag.org/content/291/5505/881.abstract Portuguese.

22. Alam M, Midtvedt T, Uribe A. Differential cell kinetics in the ileum and colon of germfree rats. Scandinavian Journal of Gastroenterology. [Internet] 1994:29(5)445-51. Available from: http://informahealthcare.com/doi/abs/10.3109/00365529409096836 Portuguese. 